\title{
Five new species of Trichoderma from moist soils in China
}

\author{
Guang-Zhi Zhang', He-Tong Yang', Xin-Jian Zhang', Fang-Yuan Zhou', \\ Xiao-Qing Wu', Xue-Ying Xie', Xiao-Yan Zhao', Hong-Zi Zhou' \\ I Qilu University of Technology (Shandong Academy of Sciences), Ecology Institute, Shandong Provincial Key \\ Laboratory for Applied Microbiology, Jinan 250103, China \\ Corresponding author: Xin-Jian Zhang (zhangxj@sdas.org)
}

Academiceditor:RungtiwaPhookamsak| Received4October2021|Accepted20January2022|Published 17 February 2022

Citation: Zhang G-Z, Yang H-T, Zhang X-J, Zhou F-Y, Wu X-Q, Xie X-Y, Zhao X-Y, Zhou H-Z (2022) Five new species of Trichoderma from moist soils in China. MycoKeys 87: 133-157. https://doi.org/10.3897/mycokeys.87.76085

\begin{abstract}
Trichoderma isolates were collected from moist soils near a water source in different areas of China. ITS sequences were submitted to MIST (Multiloci Identification System for Trichoderma) and meets the Trichoderma $\left[\mathrm{ITS}_{76}\right]$ standard. Combined analyses of phylogenetic analyses of both phylograms (tefl- $\alpha$ and $r p b 2)$ and morphological characteristics, revealed five new species of Trichoderma, namely Trichoderma hailarense, T. macrofasciculatum, T. nordicum, T. shangrilaense and T. vadicola. Phylogenetic analyses showed T. macrofasciculatum and T. shangrilaense belong to the Polysporum clade, T. hailarense, while T. nordicum and T. vadicola belong to the Viride clade. Each new taxon formed a distinct clade in phylogenetic analysis and have unique sequences of tef1- $\alpha$ and $r p b 2$ that meet the Trichoderma new species standard. The conidiation of T. macrofasciculatum typically appeared in white pustules in concentric rings on PDA or MEA and its conidia had one or few distinctly verrucose. Conidiophores of T. shangrilaense are short and rarely branched, phialides usually curved and irregularly disposed. The aerial mycelium of T. hailarense and T. vadicola formed strands to floccose mat, conidiation tardy and scattered in tufts, conidiophores repeatedly rebranching in dendriform structure. The phialides of T. nordicum lageniform are curved on PDA and its conidia are globose to obovoidal and large.
\end{abstract}

\section{Keywords}

Hypocreales, phylogenetic analysis, soil fungi, Sordariomycetes, taxonomy

Copyright Guang-Zhi Zhang et al. This is an open access article distributed under the terms of the Creative Commons Attribution License (CC BY 4.0), which permits unrestricted use, distribution, and reproduction in any medium, provided the original author and source are credited. 


\section{Introduction}

The genus Trichoderma belongs to one of the most useful groups of microbes to have had an impact on human welfare in recent times. They are most widely used as biofungicides and plant growth modifiers and are sources of enzymes of industrial utility, including those used in the biofuels industry (Mukherjee et al. 2013). Some Trichoderma species have great potential applications to remediate soil and water pollution (Tripathi et al. 2013). Trichoderma is a hyperdiverse fungal genus (Jaklitsch and Voglmayr 2015). Formerly the species-level identification of Trichoderma was performed, based on their morphological characteristics (Gams and Bissett 1998) and is becoming more and more difficult because there are only a few relatively invariable morphological characteristics, leading to overlap amongst species (Samuels 2006).

DNA sequence analysis was introduced and provided more reliable identification of Trichoderma species (Druzhinina et al. 2006; Samuels 2006; Samuels et al. 2006). Given their low sequence variability or missing adequate sequence data, ITS, call and chi18-5 are rarely used for new Trichoderma species identifications (Bissett et al. 2015; Cai and Druzhinina 2021). TefI- $\alpha$ and $r p b 2$ facilitate reliable species identifications through phylogenetic analyses (Bissett et al. 2015; Jaklitsch and Voglmayr 2015; Cai and Druzhinina 2021) and have been used in the phylogenetic analysis and identification of new Trichoderma species in recent years. This has resulted in the exponential expansion of Trichoderma taxonomy, with up to 20 new species recognised per year (Cai and Druzhinina 2021). As of July 2021, a total of 405 species has been reported and recognised (Bustamante et al. 2021; Cai and Druzhinina 2021; Rodríguez et al. 2021; Zheng et al. 2021). The new molecular identification protocol provides a standard for the molecular identification of Trichoderma (Cai and Druzhinina 2021; www. trichoderma.info). According to this protocol, the new species should meet the Trichoderma $\left[\mathrm{ITS}_{76}\right]$ standard and has unique sequences of rpb2 or tef1 (does not meet the $s p \exists !\left(r p b 2_{99} \cong t e f 1_{97}\right)$ standard for known species).

Trichoderma species are cosmopolitan and prevalent components of different ecosystems in a wide range of climatic zones (Kubicek et al. 2008). They are mainly found in natural soils and decaying wood and plant material (Kredics et al. 2014). Many new Trichoderma species were first discovered in China, with up to 115 new Trichoderma species being reported since 2016 (Zhu and Zhuang 2015a, b, 2018; Chen and Zhuang 2016, 2017a, b, c, d; Qin and Zhuang 2016a, b, c, 2017; Sun et al. 2016; Zeng and Zhuang 2017, 2019; Zhang and Zhuang 2017, 2018, 2019; Li et al. 2018; Qiao et al. 2018; Zhao et al. 2018; Ding et al. 2020; Gu et al. 2020; Liu et al. 2020; Zheng et al. 2021). Amongst these 115 species, 75 were isolated from soils, 36 were collected from the plant branch or rotten twigs, while the other four species were collected from mushroom, pollen or rotten fruit.

Trichoderma has been segregated into many clades (Bissett 1991; Atanasova et al. 2013). The Polysporum clade (formerly section Pachybasium) was first defined by Bissett (1991), including 20 species. However, molecular phylogeny has shown that it is paraphyletic (Kindermann et al. 1998; Kullnig-Gradinger et al. 2002) and the species composition was subdivided subsequently into five unrelated clades, such as Ceram- 
ica, Chlorospora, Harzianum, Semiorbis, Strictipilosa or Stromaticum (Chaverri and Samuels 2003; Jaklitsch 2009; Jaklitsch 2011). Trichoderma hamatum and some other species were found to belong to the section Trichoderma. The removal of T. hamatum determined that Bissett's sectional name could not be used anymore. Lu et al. (2004) refined the clade containing the remaining species around T. polysporum/Hypocrea pachybasioides and it was named the Pachybasium core group by Jaklitsch (2011), which includes 13 species. In subsequent years, several new species were added to this clade, increasing the number of Trichoderma species to 21 species (Jaklitsch and Voglmayr 2015; Zhu and Zhuang 2015; Qin and Zhuang 2016c; Chen and Zhuang 2017b).

The Virde clade is basically in accordance with Bissett's (1991) concept, but later, some other species have been added constantly. As of 2015, this large clade has 72 species to be confirmed and described, amongst which 55 species have been well located in the six subclades (Hamatum/Asperellum, Koningii, Neorufum, Rogersonii, Viride and Viridescens) and 17 species have not been located in the unnamed branches (Park et al. 2014; Bissett et al. 2015; Jaklitsch and Voglmayr 2015). In subsequent years, 25 new species were added to this clade, increasing the number of Trichoderma species to 97 (Montoya et al. 2016; Qin and Zhuang 2016a; Chen and Zhuang 2017c; Zeng et al. 2017; Zhang and Zhuang 2017; du Plessis et al. 2018; Qiao et al. 2018; Zhang and Zhuang 2018; Crous et al. 2019; Ding et al. 2020; Tomah et al. 2020). Cai and Druzhinina (2021) reconstructed the core topology of the phylogram, based on the Maximum Likelihood (ML) phylogeny of the 361 rpb2-barcoded Trichoderma species and 361 species have been located in the eight main clades (numerically named 1-8). All Trichoderma species in the adjacent Polysporum and Viride clades were remerged into the $5^{\text {th }}$ clade, which also included several Trichoderma species from the Harzianum and lone lineage clades (Jaklitsch and Voglmayr 2015; Sun et al. 2016; Zhang and Zhuang 2017).

The present study performed the phylogenetic analysis of the five new species of Trichoderma to establish their new status. Five new species were collected from moist soils near water in different areas of China. Tef1- $\alpha$ and $r p b 2$ sequences were used for the phylogenetic reconstruction of the five new species in the present study and meet the Trichoderma new species standard (Cai and Druzhinina 2021).

\section{Materials and methods}

\section{Isolates and specimens}

Specimens were collected from Sichuan, Yunnan, Beijing, Shandong and Inner Mongolia. Trichoderma strains were isolated from soils on Trichoderma Selective Medium $\left(\mathrm{K}_{2} \mathrm{HPO}_{4} 0.90 \mathrm{~g} ; \mathrm{MgSO}_{4} \cdot 7 \mathrm{H}_{2} \mathrm{O} 0.20 \mathrm{~g} ; \mathrm{NH}_{4} \mathrm{NO}_{3} 1.0 \mathrm{~g} ; \mathrm{KCl} 0.15 \mathrm{~g}\right.$; glucose $3.0 \mathrm{~g}$; Rose Bengal $0.15 \mathrm{~g}$; Agar $15.0 \mathrm{~g}$; distilled water 1.0 litre. Post autoclaving, chloromycetin $(0.25 \mathrm{~g})$, streptomycin $(0.03 \mathrm{~g})$ and pentachloronitrobenzene $(0.2 \mathrm{~g})$ were added) (Martin 1950). Ex-type living cultures of new species were deposited in the Agricultural Culture Collection of China (ACCC) (Institute of Agricultural Resources and Regional Planning, Chinese Academy of Agricultural Sciences, Beijing, China). 


\section{Morphological characterisations}

Morphological observation of the colonies and conidium-bearing structures was based on isolates grown on PDA (potato dextrose agar, Difco), CMD (Difco cornmeal agar $+2 \% \mathrm{w} / \mathrm{v}$ dextrose), MEA (malt extract agar, Difco) and Nirenberg's SNA medium (Nirenberg 1976) for 2 weeks in an incubator at $25^{\circ} \mathrm{C}$ with alternating $12 \mathrm{~h} / 12 \mathrm{~h}$ fluorescent light/darkness. Microscopic observations were conducted with an Olympus BX53 microscope and a MicroPublisher 5.0 RTV digital camera (Olympus Corp., Tokyo, Japan). Continuous characters, such as length and width, were measured with the CellSens Standard Image software (Olympus Corp., Tokyo, Japan). Continuous measurements were based on 10-30 measured units and were reported as the extremes (maximum and minimum) in brackets separated by the mean plus and minus one standard deviation. Colour standards were from Kornerup and Wanscher (1978). Growth-rate trials were performed on $9 \mathrm{~cm}$ Petri dishes with $20 \mathrm{ml}$ of CMD, PDA, MEA and SNA at $15^{\circ} \mathrm{C}, 20^{\circ} \mathrm{C}, 25^{\circ} \mathrm{C}, 30^{\circ} \mathrm{C}$, and $35^{\circ} \mathrm{C}$. Petri dishes were incubated in darkness up to 1 week or until the colony covered the agar surface. Colony radii were measured daily. Trials were replicated three times.

\section{DNA extraction, polymerase chain reaction (PCR) and sequencing}

Strains were grown in $9 \mathrm{~cm}$-diameter Petri dishes containing PDA (potato dextrose agar, Difco). Cultures were incubated at $25^{\circ} \mathrm{C}$ for ca. 3-5 days. Genomic DNA was extracted from the mycelial mat harvested from the surface of the broth with the Fungal Genomic DNA Extraction Kit (Aidlab Biotechnologies Co. Ltd., Beijing, China). The amplification of ITS was performed using the primer pair ITS5 and ITS4 (White et al. 1990), for tef1- $\alpha$, primer pair EF1-728F (Carbone and Kohn 1999) and tef1-ALLErev (Jaklitsch et al. 2005) was used and, for $r p b 2$, primer pair frpb2-5f and frpb2-7cr (Liu et al. 1999) was used. PCR amplification of each gene was performed as described by Park et al. (2014) and Chaverri et al. (2011). PCR products were purified and sequenced by ABI3730 Gene Analyzer at Sangon (Sangon Biotech (Shanghai) Co., Ltd.).

\section{Molecular identification and phylogenetic analyses}

We followed the molecular identification protocol for a single Trichoderma isolate (Cai and Druzhinina 2021; www.trichoderma.info) and estimated the pairwise similarity between the ITS sequence of the query strain and the sequences that are given in the ITS56 datasets (Cai and Druzhinina 2021). Tef1- $\alpha$ and $r p b 2$ sequences were subjected to Multiloci Identification System for Trichoderma (MMIT) (mmit.china-cctc. org) (Dou et al. 2020) and NCBI nucleotide BLAST (https://blast.ncbi.nlm.nih.gov/ Blast.cgi) to detect the most closely related species. A sufficient number of representative sequences $(n>6)$ of Trichoderma species (Bissett et al. 2015; Cai and Druzhinina 2021) that are closely related to the new species were chosen for phylogenetic analyses. Protocrea illinoensis and Protocrea farinose were selected as outgroups. 
Sequences were aligned with ClustalW (Thompson et al. 1994) and adjusted manually. Gaps were treated as missing data. Phylogenetic analyses were performed with tef1- $\alpha$ or $r p b 2$ with MEGA-X software (Kumar et al. 2018). Model testing was used to find the best DNA model for ML analyses. The stability of clades was evaluated by bootstrap tests with 1000 replications. Bootstrap values above 50\% were indicated on the corresponding branches. Maximum Parsimony (MP) analyses were performed with MEGA-X software (Kumar et al. 2018) using 1000 replicates of heuristic search with the random addition of sequences and tree bisection reconnection as the MP search method. All molecular characters were weighted equally and gaps were treated as missing data. Bootstrap proportions were calculated from 1000 replicates, each with 10 replicates of random addition of taxa.

\section{Results}

\section{Molecular identification and sequence analyses}

We estimated the pairwise similarity between the ITS sequence of the query strain and the sequences that are given in the ITS56 datasets. All the query strain belongs to the genus Trichoderma spp. with similarity value $>81 \%$ compared to the sequences in the datasets. The query strain has unique sequences of tef1- $\alpha$ and $r p b 2$ (does not meet the $s p \exists !\left(r p b 2_{99} \cong t e f 1_{97}\right)$ standard for known Trichoderma species).

Tef1- $\alpha$ or $r p b 2$ sequences of new taxon were subjected to MMIT and NCBI nucleotide BLAST and 34 representative sequences of Trichoderma species (all the species with similarity $r p b 2$ and $t e f 1-\alpha \geq 92 \%$ in the Viride clade) that are closely related to the new species, were chosen for phylogenetic analyses of $T$. hailarense, T. nordicum and T. vadicola. The accession numbers for the sequences are provided in Table 1. Model testing suggested using the Hasegawa-Kishino-Yano model (HKY; Hasegawa 1985) with gamma distributed with invariant sites $(\mathrm{HKY}+\mathrm{G}+\mathrm{I})$ for ML analyses of tef1- $\alpha$ and the Tamura-Nei model (TN93; Tamura 1993) with gamma distributed substitution rates $(\mathrm{TN} 93+\mathrm{G})$ for $r p b 2$. The phylogenetic trees from $r p b 2$ or tef1- $\alpha$ analyses are shown in Figs 1 and 2, respectively. Sequence alignments and the trees obtained were deposited in TreeBASE (http://purl.org/phylo/ treebase/phylows/study/TB2:S29166). Twenty representative sequences of closelyrelated Trichoderma species (all the Trichoderma species in the Polysporum clade) were chosen for phylogenetic analyses of $T$. macrofasciculatum and $T$. shangrilaense (Table 1). Model testing suggested using the Hasegawa-Kishino-Yano model (HKY; Hasegawa 1985) with gamma distributed substitution rates $(\mathrm{HKY}+\mathrm{G})$ for $\mathrm{ML}$ analyses of tef1- $\alpha$ and the Kimura 2-parameter (K2; Kimura 1980) with gamma distributed substitution rates $(\mathrm{K} 2+\mathrm{G})$ for $r p b 2$. The phylogenetic trees from $r p b 2$ or tef1- $\alpha$ analyses are shown in Figs 3 and 4, respectively. Sequence alignments and the trees obtained were deposited in TreeBASE (http://purl.org/phylo/treebase/phylows/study/TB2:S29166). 
Table I. Strain numbers and GenBank accession numbers of sequences used for phylogenetic analyses.

\begin{tabular}{|c|c|c|c|c|c|}
\hline \multirow[t]{2}{*}{ Species } & \multirow[t]{2}{*}{ Clade } & \multirow[t]{2}{*}{ Strain } & \multicolumn{3}{|c|}{ GenBank accession numbers } \\
\hline & & & ITS & tef $1-\alpha$ & $r p b 2$ \\
\hline T. adaptatum & Viride & HMAS 248800 & - & KX428024 & KX428042 \\
\hline T. albofulvopsis & Viride & HMAS 273760 & - & KU529127 & KU529138 \\
\hline T. alutaceum & Polysporum & CBS 120535 & FJ860725 & FJ179567 & FJ179600 \\
\hline T. appalachiense & Viride & GJS 97-243 & DQ315419 & DQ307503 & DQ307503 \\
\hline T. atlanticum & Polysporum & CBS 120632 & FJ860781 & FJ860649 & FJ860546 \\
\hline T. atroviride & Viride & CBS 119499 & FJ860726 & FJ860611 & FJ860518 \\
\hline T. bavaricum & Polysporum & CBS 120538 & FJ860737 & FJ860621 & FJ860527 \\
\hline T. beijingense & Viride & HMAS 248804 & - & KX428025 & KX428043 \\
\hline T. bifurcatum & Viride & HMAS 248795 & - & KX428018 & KX428036 \\
\hline T. caerulescens & Viride & S195 & JN715589 & JN715621 & JN715604 \\
\hline T. composticola & Viride & S590=CBS 133497 & - & KC285631 & KC285754 \\
\hline T. europaeum & Polysporum & S611 & - & KJ665489 & KJ665268 \\
\hline T. foliicola & Polysporum & Нypo 645 & JQ685871 & JQ685862 & JQ685876 \\
\hline T. gamsii & Viride & S488 & - & JN715613 & KJ 665270 \\
\hline T. hailarense & Viride & WT17901*= ACCC 39711 & MH287485 & MH287505 & MH287506 \\
\hline T. hailarense & Viride & WT17803 & MH606226 & MH606229 & MH606232 \\
\hline T. hispanicum & Viride & S453=CBS 130540 & JN715595 & JN715659 & JN715600 \\
\hline T. istrianum & Viride & S123 & - & KJ665521 & KJ665280 \\
\hline T. laevisporum & Viride & HMAS 273756 & - & KU529128 & KU529139 \\
\hline T. lacuwombatense & Polysporum & GJS 99-198 & - & KJ665547 & KJ665286 \\
\hline T. leucopus & Polysporum & CBS 122499 & FJ860764 & FJ179571 & FJ179605 \\
\hline T. luteffusum & Polysporum & CBS 120537 & FJ860773 & FJ860645 & FJ860543 \\
\hline T. macrofasciculatum & Polysporum & 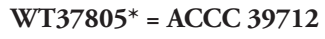 & MH287487 & MH287509 & MH287493 \\
\hline T. macrofasciculatum & Polysporum & WT37810 & MH287488 & MH287510 & MH287494 \\
\hline T. mediterraneum & Polysporum & S190 & - & KJ665568 & KJ665296 \\
\hline T. minutisporum & Polysporum & GJS 90-82 & - & KJ665618 & KJ665316 \\
\hline T. neokoningii & Viride & CBS $120070=$ GJS 04-216 & DQ841734 & KJ665620 & KJ665318 \\
\hline T. nordicum & Viride & 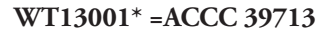 & MH287483 & MH287501 & MH287502 \\
\hline T. nordicum & Viride & WT61001 & MH287484 & MH287503 & MH287504 \\
\hline T. nybergianum & Polysporum & CBS 122500 & FJ860791 & FJ179575 & FJ179611 \\
\hline T. ochroleucum & Viride & CBS 119502 & FJ860793 & FJ860659 & FJ860556 \\
\hline T. olivascens & Viride & S475=CBS 132574 & - & KC285624 & KC285752 \\
\hline T. pachypallidum & Polysporum & CBS 122126 & FJ860798 & FJ860662 & JQ685879 \\
\hline T. palidulum & Viride & HMAS 275665 & - & MG383493 & MG383487 \\
\hline T. paratroviride & Viride & CBS136489 & - & KJ665627 & KJ665321 \\
\hline T. paraviridescens & Viride & CBS 119321 & DQ677651 & DQ672610 & KC285763 \\
\hline T. parapiluliferum & Polysporum & CBS 120921 & FJ860799 & FJ179578 & FJ179614 \\
\hline T. piluliferum & Polysporum & CBS 120927 & FJ860810 & FJ860674 & FJ179615 \\
\hline T. placentula & Polysporum & CBS 120924 & - & FJ179580 & FJ179616 \\
\hline T. polysporum & Polysporum & СРК 3131 & - & FJ860661 & FJ860558 \\
\hline T. pruinosum & Polysporum & HMAS 247217 & - & MF371227 & MF371212 \\
\hline T. samuelsii & Viride & S5=CBS 130537 & JN715593 & JN715651 & JN715599 \\
\hline T. sempervirentis & Viride & S599=CBS 133498 & - & KC285632 & KC285755 \\
\hline T. seppoi & Polysporum & CBS 122498 & - & FJ179581 & FJ179617 \\
\hline T. shangrilaense & Polysporum & WT34004* = ACCC 39714 & MH287489 & MH287495 & MH287496 \\
\hline T. shangrilaense & Polysporum & WT40502 & MH606224 & MH606227 & MH606230 \\
\hline T. shaoguanicum & Viride & HMAS 248809 & - & KX428031 & KX428049 \\
\hline T. sinoluteum & Polysporum & HMAS 252868 & - & KJ634777 & KJ634744 \\
\hline T. speciosum & Viride & CGMCC 3.19079 & MH113929 & MH183184 & MH155270 \\
\hline T. sphaerosporum & Viride & HMAS 273763 & - & KU529134 & KU529145 \\
\hline T. subviride & Viride & HMAS 273761 & - & KU529131 & KU529142 \\
\hline T. tardum & Viride & HMAS 248798 & - & KX428020 & KX428038 \\
\hline T. trixiae & Viride & ATCC 32630 & DQ315445 & DQ307526 & KC285770 \\
\hline
\end{tabular}




\begin{tabular}{llcccc}
\hline \multicolumn{1}{c}{ Species } & Clade & Strain & \multicolumn{2}{c}{ GenBank accession numbers } \\
\cline { 3 - 6 } & & & ITS & tef1- $\boldsymbol{\alpha}$ & $\boldsymbol{r p b 2}$ \\
\hline T. vadicola & Viride & WT10708* ACCC 39716 $^{*}$ MH287491 & MH287499 & MH287511 \\
T. vadicola & Viride & WT32801 & MH606225 & MH606228 & MH606231 \\
T. valdunense & Viride & CBS 120923 & FJ860863 & FJ860717 & FJ860605 \\
T. vinosum & Viride & GJS 99-158=CBS 119087 & AY380904 & AY376047 & KC285779 \\
T. viridarium & Viride & S136=CBS 132568 & - & KC285658 & KC285760 \\
T. viride & Viride & CBS 119327 & DQ677655 & DQ672617 & EU711362 \\
T. viridescens & Viride & S452=CBS 132573 & - & KC285646 & KC285758 \\
T. viridialbum & Viride & S250=CBS 133495 & - & KC285706 & KC285774 \\
T. virilente & Viride & S281=CBS 132569 & - & KC285692 & KC285767 \\
T. vulgatum & Viride & HMAS 248796 & - & KX428019 & KX428037 \\
Protocrea illinoensis & Outgroup & TFC 96-98 & EU703930 & EU703905 & EU703952 \\
Protocrea farinosa & Outgroup & CPK 3144 & EU703917 & EU703894 & EU703938 \\
\hline
\end{tabular}

Newly-sequenced material is indicated in bold type.
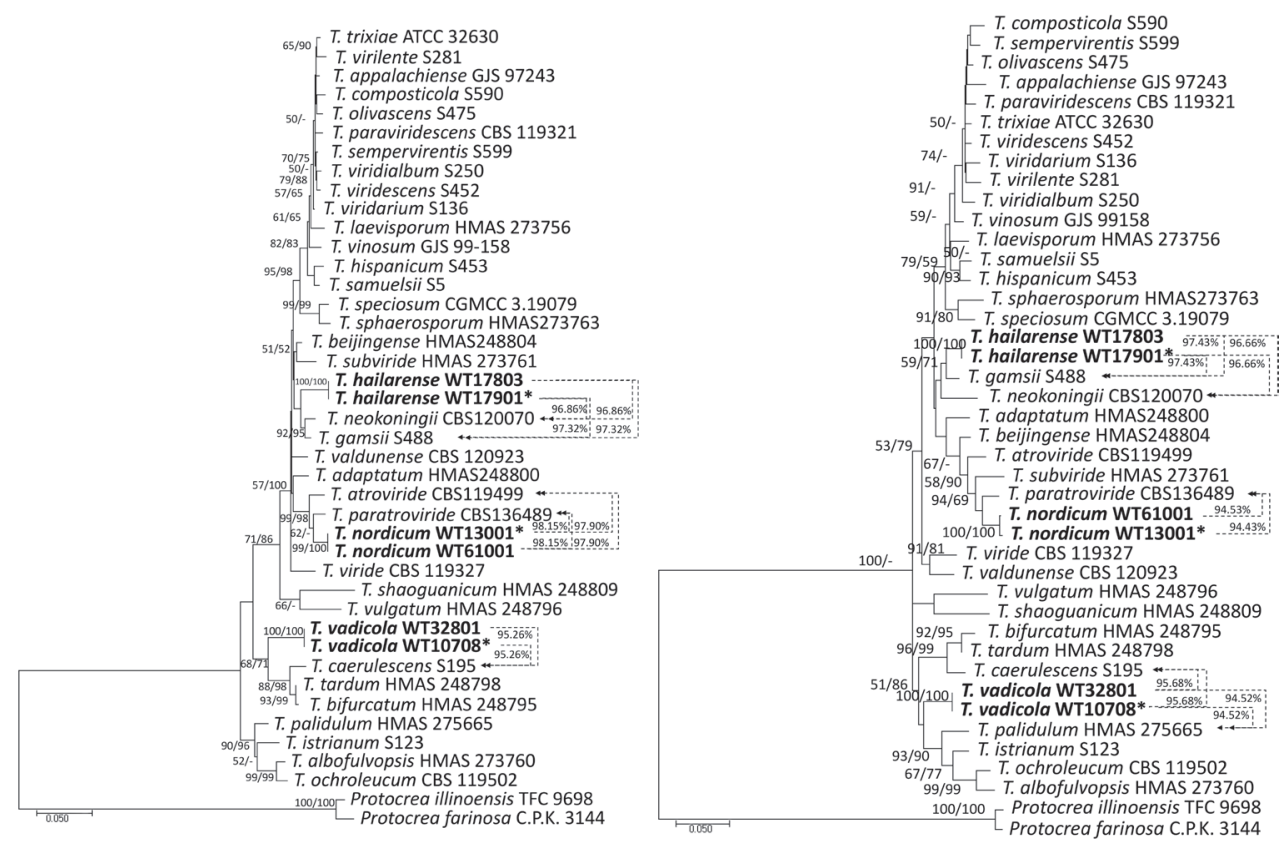

Figure I. Phylogenetic tree, based on the Maximum Likelihood analysis of the $r p b 2($ left; $\operatorname{InL}=-5930.92)$ and tef1- $\alpha$ (right; InL = -7681.95) dataset. Bootstrap values of Maximum Likelihood (left) and Maximum Parsimony (right) above $50 \%$ are indicated at the nodes. The tree is rooted with Protocrea illinoensis TFC 9698 and $P$. farinose CPK 3144. New species proposed here are indicated in bold. The type strains are indicated with an asterisk $\left(^{*}\right)$ after the strain number. Results of the pairwise sequence similarity are illustrated on the dashed lines between the query strain and its closely-related species (arrows point to the reference strains).

The MP analyses using tef1- $\alpha$ and $r p b 2$ (Fig. 1) resulted in topologically similar trees with minor differences. Each new taxon of Trichoderma formed a distinct clade and meets the Trichoderma new species standard (does not meet the $s p \exists !\left(r p b 2_{99} \cong t e f 1_{97}\right)$ standard for known Trichoderma species) (Cai and Druzhinina 2021). The similarity value between the new species and the reference strain is shown in the number on the right side of the phylogenetic trees. 

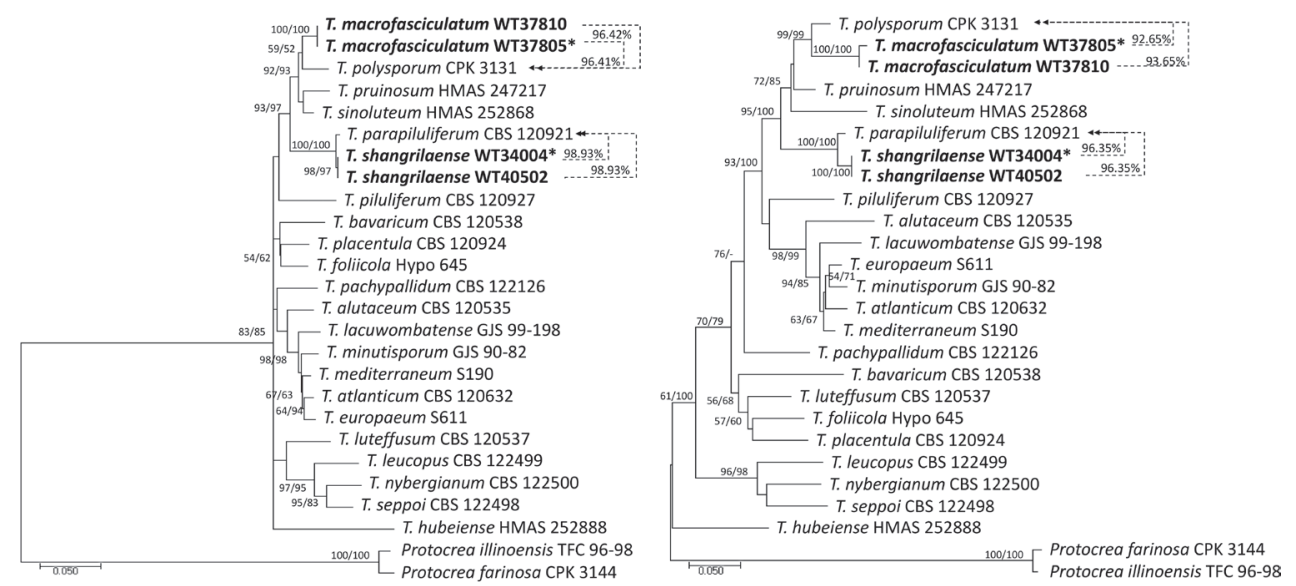

Figure 2. Phylogenetic tree based on the Maximum Likelihood analysis of the $r p b 2$ (left; $\mathrm{InL}=-5912.02$ ) and tef $1-\alpha$ (right; InL = -9060.53) dataset. Maximum Likelihood bootstrap values (left) and MPBP (right) above 50\% are indicated at the nodes. The tree is rooted with Protocrea illinoensis TFC 9698 and P. farinose CPK 3144. New species proposed here are indicated in bold. The type strains are indicated with an asterisk $\left(^{*}\right)$ after the strain number. Results of the pairwise sequence similarity are illustrated on the dashed lines between the query strain and its closely-related species (arrows point to the reference strains).

Trichoderma hailarense clearly separated from T. gamsii S488 (with similarity rpb2 $=97.32 \%$ and $t e f 1-\alpha=97.43 \%$ ) and T. neokoningii CBS120070 (with similarity rpb2 $=96.86 \%$ and $t e f 1-\alpha=96.66 \%)$. Trichoderma nordicum was associated, but clearly separated from T. paratroviride CBS136489 with similarity $r p b 2=98.15 \%$ and $t e f 1=$ 94.43\%. Trichoderma vadicola was associated, but clearly separated from T. caerulescens S195 (with similarity 95.26\%), T. tardum HMAS 248798 (with similarity 95.57\%) and T. bifurcatum S195 (with similarity 95.76\%) in the phylogenetic tree of the rpb2. However, there were differences in the phylogenetic tree of the tef1 $-\alpha$; T. vadicola was associated and separated from T. palidulum HMAS 275665 (with similarity 94.52\%), T. istrianum S123 (with similarity 96.14\%), T. ochroleucum CBS 119502 (with similarity 93.49\%) and T. albofulvopsis HMAS 273760 (with similarity 93.16\%) (Fig. 1). The strains of T. macrofasciculatum were associated, but clearly separated from T. polysporum C.P.K. 3131 with similarity $r p b 2=96.41 \%$ and $t e f 1-\alpha=92.81 \%$; T. shangrilaense was closely related and separated from T. parapiluliferum CBS 120927 with similarity rpb2 $=98.93 \%$ and $t e f 1-\alpha=96.35 \%$ (Fig. 2).

\section{Taxonomy}

\section{Trichoderma hailarense G.Z. Zhang, sp. nov.}

MycoBank no: MB 821318

Fig. 3

Etymology. The specific epithet "hailarense" refers to the locality, the Hailar River Basin in Inner Mongolia of China where the holotype was found. 

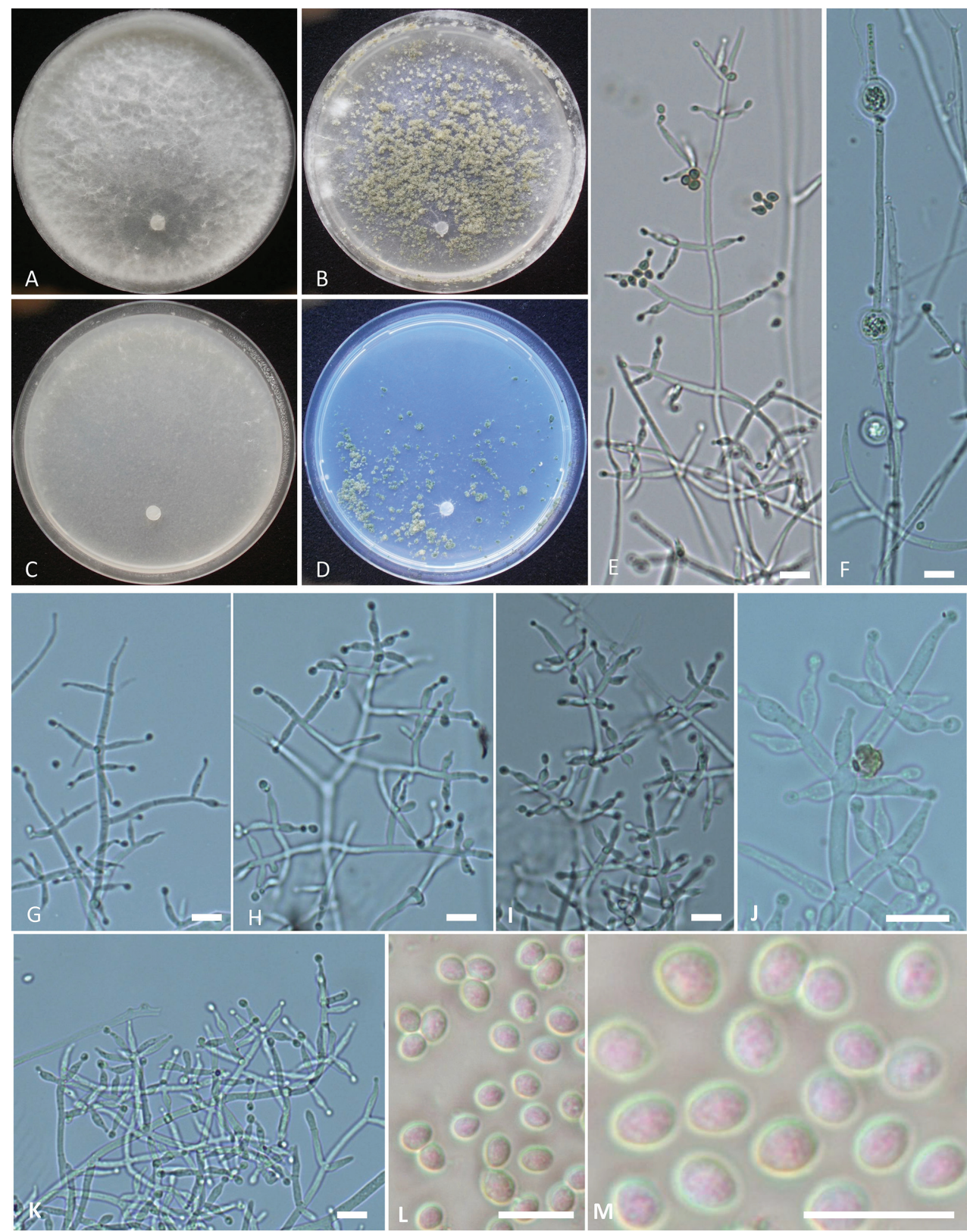

Figure 3. Trichoderma hailarense A-D cultures on different media incubated at $25^{\circ} \mathrm{C}$ for 14 days (A on PDA B on MEA $\mathbf{C}$ on CMD D on SNA) E, G-K conidiophores and phialides $\mathbf{F}$ chlamydospores L, $\mathbf{M}$ conidia. Notes: $\mathbf{E}$ on MEA F-M on PDA A-M from WT17901. Scale bars: $10 \mu \mathrm{m}(\mathbf{E}-\mathbf{J})$.

Typification. China. Inner Mongolia, Hailar River Basin, 618 m (altitude), isolated from soil, 17 September 2016, G.Z. Zhang (Holotype WT 17901).

Diagnosis. Phylogenetically, Trichoderma hailarense formed a distinct clade and is related to T. gamsii and T. neokoningii (Fig. 1). The sequence similarity of $r p b 2$ 
with T. gamsii S488 and T. neokoningii CBS120070 was $97.32 \%$ and $96.86 \%$, respectively and the sequence similarity of tef1- $\alpha$ with T. gamsii S488 and T. neokoningii CBS120070 was $97.43 \%$ and $96.66 \%$, respectively. Colonies of T. hailarense did not form conidia on PDA and conidia of T. hailarense on other media were obovoid, delicately roughened and easily distinguished from those of T. gamsii and T. neokoningii.

Teleomorph. Unknown.

Growth optimal at $30^{\circ} \mathrm{C}$, slow at $35^{\circ} \mathrm{C}$ on all media. Colony radius after $72 \mathrm{~h}$ at $30^{\circ} \mathrm{C} 53-56 \mathrm{~mm}$ on PDA, 54-56 mm on CMD, 33-37 mm on MEA and 33-36 mm on SNA. Colony radius after $72 \mathrm{~h}$ at $35^{\circ} \mathrm{C} 13-15 \mathrm{~mm}$ on PDA, $10-14 \mathrm{~mm}$ on CMD, 9-12 mm on MEA and 10-12 mm on SNA. Aerial mycelia abundant, arachnoid on PDA after $72 \mathrm{~h}$ at $25^{\circ} \mathrm{C}$ under $12 \mathrm{~h}$ photoperiod. Conidiation started around the inoculation point after 7 days on PDA, with relatively few or small conidia. Diffusing pigment or distinctive odour absent. Conidiation started around the inoculation point after 7 days on MEA, forming a few large pustules, cream yellow. On SNA, aerial mycelia were few, forming a few large pustules around the inoculation point in age, cream-yellow. Conidiophores and branches narrow and flexuous, tending to be regularly verticillate, forming a pyramidal structure, with each branch terminating in a cruciate whorl of up to five phialides. Phialides, lageniform, (8.0-)9.4-13.1(-15.5) $\times$ $(2.5-) 3.0-3.5(-3.6) \mu \mathrm{m}($ mean $=11.2 \times 3.3 \mu \mathrm{m})$, base 1.8-2.5 $\mu \mathrm{m}($ mean $=2.1 \mu \mathrm{m})$; phialide length/width ratio $(2.33-) 2.7-4.4(-5.9)$ (mean =3.4). Conidia obovoid, (4.2) 4.3-4.7(-4.9) $\times(3.4-) 3.6-3.9(-4.1) \mu \mathrm{m}($ mean $=4.5 \times 3.7 \mu \mathrm{m})$, length/width ratio 1.1-1.4 $($ mean $=1.2)$, delicately roughened. Chlamydospores: $(7.0-) 7.5-8.2(-8.5) \times$ (6.5-)7.0-7.5(-8.3) $\mu \mathrm{m}$.

Distribution. China. Inner Mongolia.

Additional specimen examined. China. Inner Mongolia, Hulun Buir, $610 \mathrm{~m}$ (altitude), isolated from soil, 17 September 2016, J.D. Hu (WT17905).

Notes. Phylogenetically Trichoderma hailarense is related to T. gamsii and T. neokoningii (Fig. 1) and does not meet the $s p \exists !\left(r p b 2_{99} \cong t e f 1_{97}\right)$ standard for T. gamsii or T. neokoningii. Morphologically, colonies of T. gamsii and T. neokoningii on PDA formed conidia sporadically or in hemispherical pustules and conidia of T. gamsii and T. neokoningii were ellipsoidal to oblong, smooth-walled (Jaklitsch et al. 2006). However, colonies of T. hailarense did not form conidia on PDA and conidia of T. hailarense on other media were obovoid, delicately roughened and easily distinguished from those of T. gamsii and T. neokoningii.

\section{Trichoderma macrofasciculatum G.Z. Zhang, sp. nov.}

MycoBank no: MB 821299

Fig. 4

Etymology. The specific epithet "macrofasciculatum" refers to the morphological feature of the conidiation, conidiophores aggregated into large fascicles in concentric rings.

Typification. China, Sichuan, Nine-Village Valley, $2405 \mathrm{~m}$ (altitude), isolated from soil, 24 September 2016, G.Z. Zhang (Holotype WT 37805). 

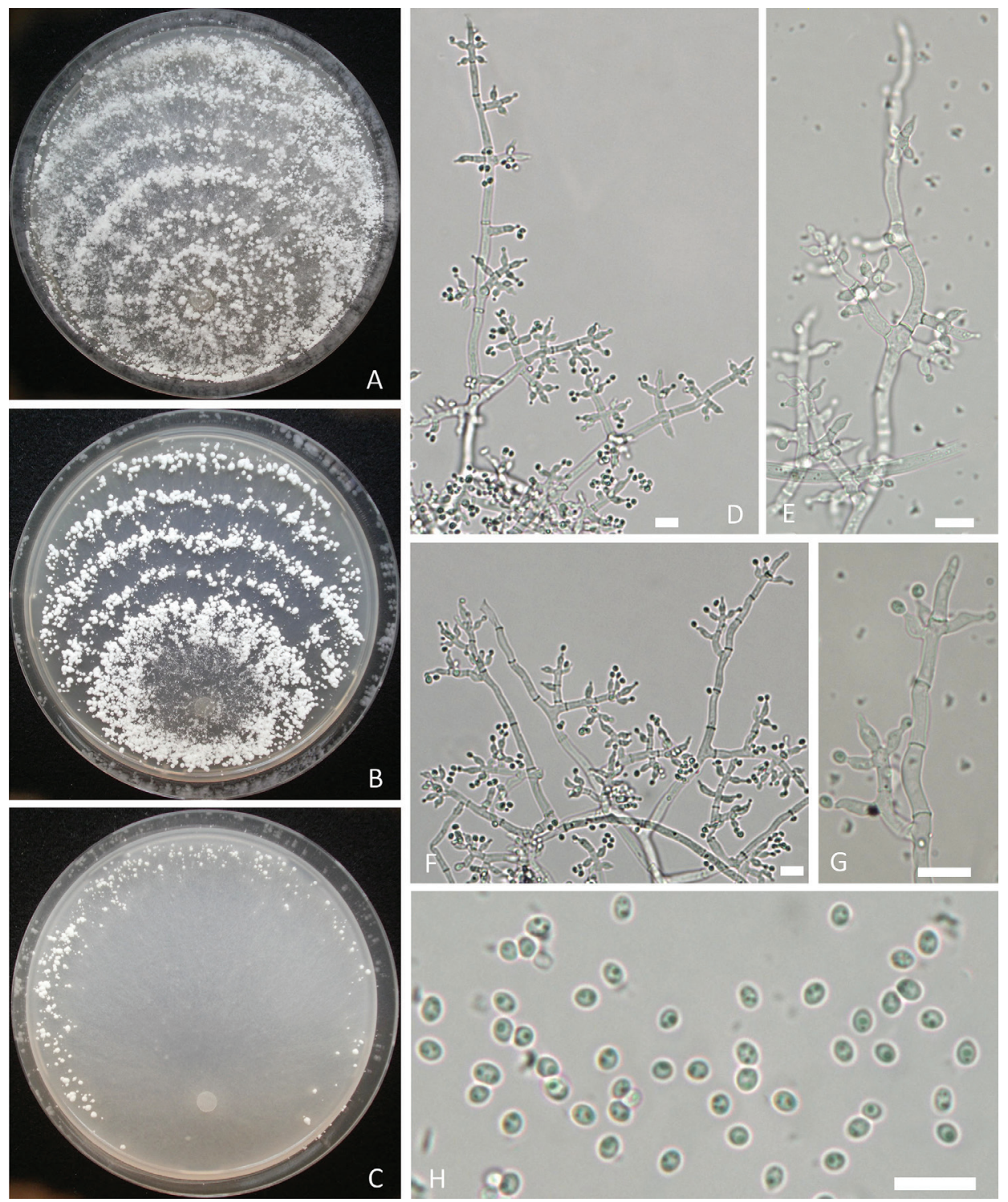

Figure 4. Trichoderma macrofasciculatum $\mathbf{A}-\mathbf{C}$ cultures on different media incubated at $25^{\circ} \mathrm{C}$ for 7 days (A on PDA B on MEA C on CM) D-G conidiophores and phialides $\mathbf{H}$ conidia with guttules. Notes: A, D, E from WT37810 B, C, F, G from WT37805. Scale bars: $10 \mu \mathrm{m}(\mathbf{D}-\mathbf{H})$.

Diagnosis. Phylogenetically, Trichoderma macrofasciculatum WT37805 and WT37810 formed a distinct clade and is related to T. polysporum C.P.K. 3131 in the Polysporum clade, but the similarities of rpb2 and tefl- $\alpha$ between these two species were only $96.41 \%$ and $92.81 \%$, respectively. Trichoderma macrofasciculatum cannot grow at $35^{\circ} \mathrm{C}$ as T. polysporum and the former formed large and white pustules in concentric rings at $25^{\circ} \mathrm{C}$, elongations were rarely observed and conidia had few guttules, which are distinct from T. polysporum. 
Teleomorph. Unknown.

Growth optimum at $20{ }^{\circ} \mathrm{C}$, slow or limited at $30{ }^{\circ} \mathrm{C}$, absent at $35^{\circ} \mathrm{C}$. Colony radius after $72 \mathrm{~h}$ at $25^{\circ} \mathrm{C} 21-24 \mathrm{~mm}$ on PDA, 23-27 mm on CMD, 17-20 mm on MEA and 12-16 mm on SNA. Aerial mycelia abundant on PDA and MEA after incubation for $72 \mathrm{~h}$ at $25^{\circ} \mathrm{C}$ under a $12 \mathrm{~h}$ photoperiod. Conidiation typically in pustules in concentric rings on PDA, solitary or aggregated, producing a farinose to granular mat. Diameter of pustules up to $2.2 \mathrm{~mm}$, pompon-like, white. Diffusing pigment and distinct odour absent. Conidiation on MEA typically in pustules in concentric rings, pompon-like as on PDA. On CMD, aerial mycelia sparsely developed. Conidiation aggregated in sporadic pustules near the colony margin, white. On SNA, aerial mycelia few and conidiation not observed. Conidiophores and branches irregularly branched in a dendriform structure, with each branch terminating in a cruciate whorl of up to five phialides. Hyphal septa clearly visible. Phialides flask-shaped, often curved, $(4.9-) 5.6-7.8(-8.8) \times(2.8-) 3.0-3.2(-3.4) \mu \mathrm{m}($ mean $=6.7 \times 3.1 \mu \mathrm{m}), 1.8-2.6 \mu \mathrm{m}$ $($ mean $=2.2 \mu \mathrm{m})$ near the base; phialide length/width ratio (1.5-)1.8-2.4(-2.8) (mean $=2.1$ ) . Conidia subglobose to ellipsoid, hyaline, smooth, with one or few distinctly verrucose, $(2.6-) 2.8-3.3(-3.6) \times(2.4-) 2.5-2.7(-2.9) \mu \mathrm{m}($ mean $=3.0 \times 2.6 \mu \mathrm{m})$, length/width ratio $1.0-1.3($ mean $=1.2)$. Chlamydospores not observed.

Distribution. China, Sichuan Province.

Additional material examined. China, Sichuan, Nine-Village Valley, $2405 \mathrm{~m}$ (altitude), isolated from soil, 24 September 2016, G.Z. Zhang (WT 37810).

Notes. Phylogenetically Trichoderma macrofasciculatum WT 37805 is related to T. polysporum C.P.K. 3131 in the Polysporum clade (Fig. 1), but the similarities of rpb2 and tef $1-\alpha$ between these two species were only $96.41 \%$ and $92.81 \%$ respectively, with 94 and $41 \mathrm{bp}$ differences amongst 1311 and $1152 \mathrm{bp}$. Trichoderma macrofasciculatum cannot grow at $35^{\circ} \mathrm{C}$ as T. polysporum and the former formed large and white pustules in concentric rings at $25^{\circ} \mathrm{C}$, elongations were rarely observed and conidia had few guttules, which are distinct from T. polysporum (Lu et al. 2004).

\section{Trichoderma nordicum G.Z. Zhang, sp. nov.}

MycoBank no: MB 8212301

Fig. 5

Etymology. "nord" means found in the north of China.

Holotype. China, Beijing, Yu-yuan-tan Park, 43 m (altitude), isolated from soil, 27 October 2016, G.Z. Zhang (Holotype WT 13001), ex-type culture ACCC 39713.

Diagnosis. Phylogenetically Trichoderma nordicum is related to T. paratroviride, but the sequence similarities of $r p b 2$ and tef $1-\alpha$ were $98.15 \%$ and $94.43 \%$, respectively. That does not meet the $s p \exists !\left(r p b 2_{99} \cong t e f 1_{97}\right)$ standard for T. paratroviride or other known Trichoderma species. Morphologically, conidiophores of T. paratroviride consisting of a main axis and often distantly-spaced side branches, not re-branching. Conidiophores of $T$. nordicum are branched in a more complex manner; conidia are larger than those of T. paratroviride. 

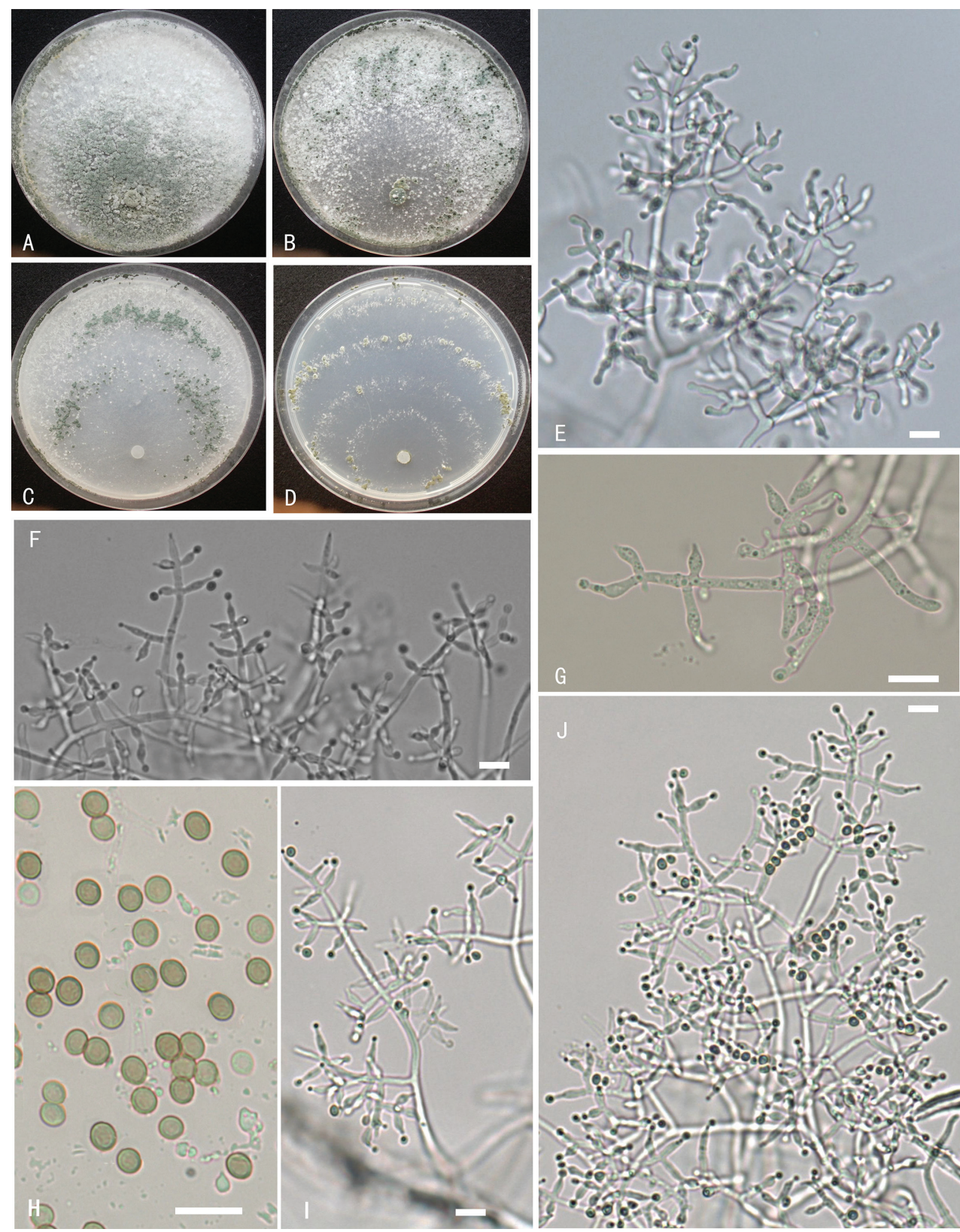

Figure 5. Trichoderma nordicum A-D cultures on different media at $25^{\circ} \mathrm{C}$ after 10 days (A on PDA $\mathbf{B}$ on MEA $\mathbf{C}$ on CMD D on SNA) E-G, I, J conidiophores and phialides $\mathbf{H}$ conidia. Notes: $\mathbf{E}$ on PDA F-J on MEA A-D from WT13001 E-J from WT61001. Scale bars: $10 \mu \mathrm{m}($ E-J).

Teleomorph. Unknown.

Growth optimal at $25^{\circ} \mathrm{C}$, slow or limited at $30^{\circ} \mathrm{C}$, absent at $35^{\circ} \mathrm{C}$. Colonies grew fast on PDA, CMD and MEA and slow on SNA. Colony radius after $72 \mathrm{~h}$ at $25^{\circ} \mathrm{C}$ 67-71 $\mathrm{mm}$ on PDA, 68-71 $\mathrm{mm}$ on CMD, 51-55 $\mathrm{mm}$ on MEA and $21-24 \mathrm{~mm}$ on 
SNA. Aerial mycelia sparse on PDA after $72 \mathrm{~h}$ at $25^{\circ} \mathrm{C}$ under $12 \mathrm{~h}$ photoperiod and conidiation developed within $48 \mathrm{~h}$ beginning at the inoculation point and progressed around, grey-white at first and slowly turning green. Diffusing pigment or distinctive odour absent. Aerial mycelia sparse and flocculence on MEA after $72 \mathrm{~h}$ at $20{ }^{\circ} \mathrm{C}$ under $12 \mathrm{~h}$ photoperiod. Conidia developed within $48 \mathrm{~h}$ beginning near the colony margin on MEA, grey-white at first and slowly turning green, transparent liquid secreted. Aerial mycelia few on SNA and CMD after $72 \mathrm{~h}$ at $25^{\circ} \mathrm{C}$, conidia formed around the inoculation point and in distinct concentric rings after $96 \mathrm{~h}$ under $12 \mathrm{~h}$ photoperiod on SNA and CMD, diffusing pigment not produced. Conidiophores and branches narrow and flexuous, tending to be regularly verticillate forming a pyramidal structure, each branch terminating in a cruciate whorl of up to five phialides. Phialides, lageniform, $(6.2-) 7.2-10.3(-12.9) \times(2.6-) 2.9-3.2(-3.4) \mu \mathrm{m}($ mean $=8.8 \times 3.1 \mu \mathrm{m})$, 1.6-2.3 $\mu \mathrm{m}$ (mean $=1.9 \mu \mathrm{m})$ near the base; phialide length/width ratio $(2.1-) 2.4-$ $3.4(-4.3)$ (mean = 2.9). On PDA, phialides curved, distinguished from those on other media. Conidia, globose to obovoidal, (4.1-)4.4-4.8(-5.0) $\times(4.0-) 4.1-4.4(-4.6) \mu \mathrm{m}$ $($ mean $=4.6 \times 4.3 \mu \mathrm{m})$, length $/$ width ratio $1.0-1.2($ mean $=1.1)$. Chlamydospores sometimes present, $(8.7-) 9.8 \times 10.4(-12.5) \mu \mathrm{m}$.

Distribution. China, Beijing and Hebei.

Additional specimen examined. China. Hebei, Bai-yang Lake, 19 m (altitude), isolated from soil, 15 September 2016, J.S. Li (WT 61001).

Notes. Phylogenetically, Trichoderma nordicum is related to $T$. paratroviride (Fig. 1), but the sequence similarities of $r p b 2$ and tef $1-\alpha$ were $98.15 \%$ and $94.43 \%$, respectively. That does not meet the $s p \exists !\left(r p b 2_{99} \cong t e f 1_{97}\right)$ standard for T. paratroviride or other known Trichoderma species. Morphologically, conidiophores of $T$. paratroviride consist of a main axis and often distantly-spaced side branches, not re-branching. Conidiophores of $T$. nordicum are branched in a more complex manner; conidia are larger than those of T. paratroviride (Jaklitsch and Voglmayr 2015).

\section{Trichoderma shangrilaense G.Z. Zhang, sp. nov.}

MycoBank no: MB 821300

Fig. 6

Etymology. "shangrilaense" was originally found at Shangrila in Yunnan Province of China.

Typification. China. Yunnan, Pudacuo National Park, $3611 \mathrm{~m}$ (altitude), isolated from soil, 21 June 2016, G.Z. Zhang (Holotype WT 34004), Ex-type culture ACCC 39714.

Diagnosis. Phylogenetically, Trichoderma shangrilaense is related to T. parapiluliferum (CBS 120921) (Fig. 1), but the sequence similarity of rpb2 between these two species was $98.93 \%$ and the sequence similarity of tefl- $\alpha$ was $96.35 \%$. That does not meet the $s p \exists !\left(r p b 2_{99} \cong t e f 1_{97}\right)$ standard for T. parapiluliferum or other known Trichoderma species. Conidiophore main axis of $T$. shangrilaense fertile to apex, conidia obovoid to ellipsoid, easily distinguished from that of T. parapiluliferum. 


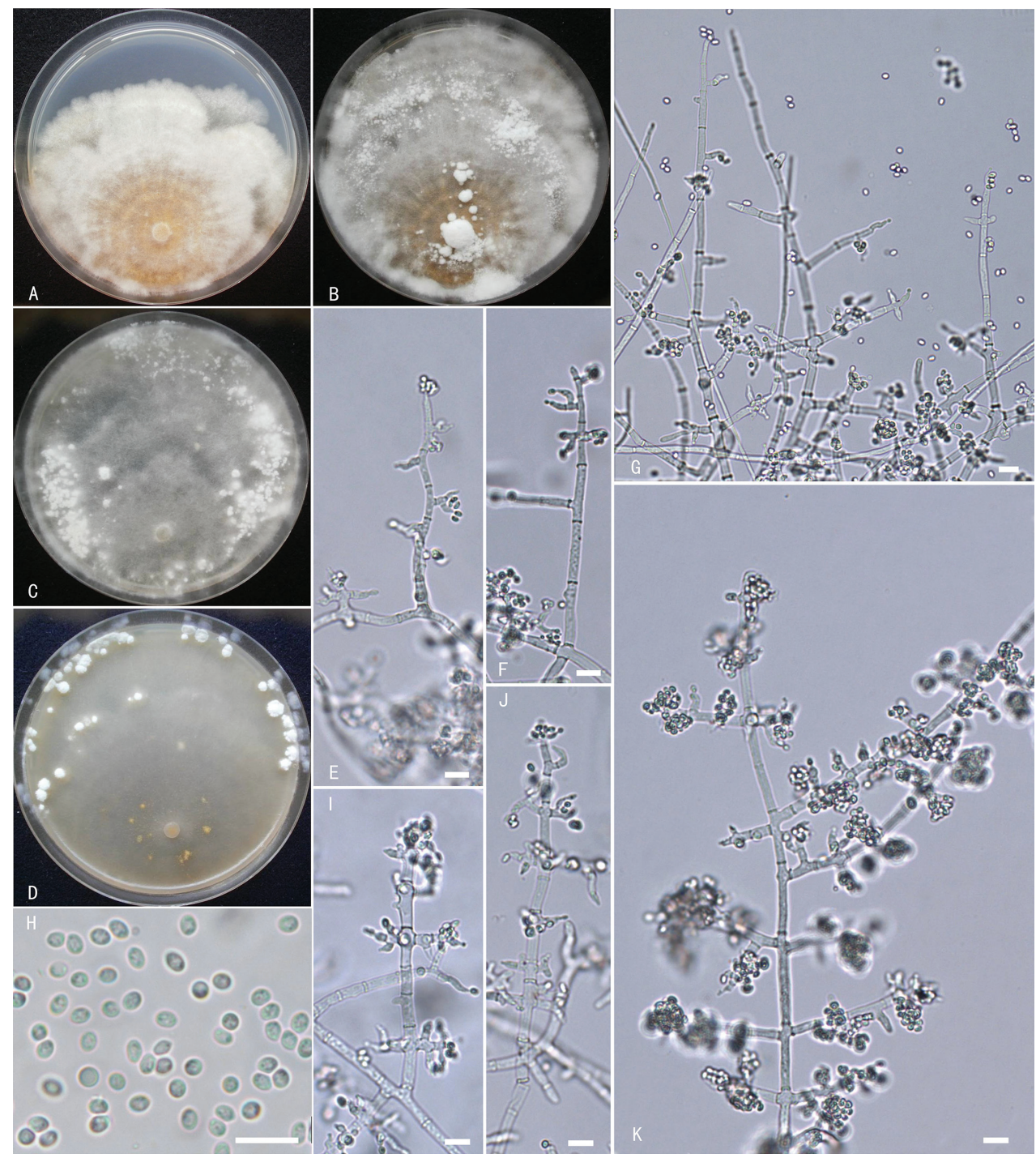

Figure 6. Trichoderma shangrilaense $\mathbf{A}-\mathbf{D}$ cultures (A on PDA, $25^{\circ} \mathrm{C}, 10$ days $\mathbf{B}$ on PDA, $25^{\circ} \mathrm{C}, 21$ days $\mathbf{C}$ on MEA, $25^{\circ} \mathrm{C}, 21$ days $\mathbf{D}$ on $\mathrm{CMD}, 25^{\circ} \mathrm{C}, 21$ days) $\mathbf{E}-\mathbf{G}, \mathbf{I}-\mathbf{K}$ conidiophores and phialides $\mathbf{H}$ conidia A-K from WT34004. Scale bars: $10 \mu \mathrm{m}(\mathbf{E}-\mathbf{K})$.

Teleomorph. Unknown.

Growth optimal at $20^{\circ} \mathrm{C}$, slow, limited at $25^{\circ} \mathrm{C}$ and absent at $30{ }^{\circ} \mathrm{C}$ or $35{ }^{\circ} \mathrm{C}$. Colony radius after $72 \mathrm{~h}$ at $20^{\circ} \mathrm{C} 19-21 \mathrm{~mm}$ on PDA, 23-24 mm on CMD, 19$21 \mathrm{~mm}$ on MEA and 8-11 mm on SNA. Aerial mycelia abundant, compact on PDA after 7 days at $20{ }^{\circ} \mathrm{C}$ under $12 \mathrm{~h}$ photoperiod, conidiation not easily formed and a yellow diffusing pigment developed near the inoculation point; conidiation formed unequal in size, white pustules after 14 days. Conidiophores and branches narrow and 
flexuous, forming a dendriform structure and irregularly branched, not rebranched, main axis to 4.3-5.0 $\mu \mathrm{m}$ wide, fertile to apex. Phialides, flask-shaped, often curved, $(4.5-) 5.7-9.0(-11.1) \times(2.9-) 3.2-3.5(-4.1) \mu \mathrm{m}($ mean $=7.4 \times 3.4 \mu \mathrm{m}), 1.6-3.4 \mu \mathrm{m}$ wide $($ mean $=2.6 \mu \mathrm{m})$ near the base; phialide length/width ratio $(1.5-) 2.0-2.6(-3.0)$ $($ mean $=2.3)$. Conidia, obovoid to ellipsoidal, smooth, $(3.3-) 3.5-4.0(-4.4) \times$ $(2.8-) 3.0-3.3(-3.5) \mu \mathrm{m}($ mean $=3.8 \times 3.19 \mu \mathrm{m})$, length $/$ width ratio $1.1-1.4($ mean $=$ 1.2). Chlamydospores not observed.

Colony radius $28-33 \mathrm{~mm}$, aerial mycelia abundant and floccose after 7 days at $20^{\circ} \mathrm{C}$ under $12 \mathrm{~h}$ photoperiod. Conidiation slowly developing on MEA. After about 14 days, pompon-like, white fascicles developed. No diffusing pigment observed. On CMD after 7 days at $20^{\circ} \mathrm{C}$ under $12 \mathrm{~h}$ photoperiod, colony radius $28-33 \mathrm{~mm}$, aerial mycelia few. Conidiation formed flat or cushion-shaped pustules near the colony margin after 21 days and a yellow diffusing pigment developed near the inoculation point. On SNA after 7 days at $20^{\circ} \mathrm{C}$ under $12 \mathrm{~h}$ photoperiod, colony mycelia sparse and no conidiation formed. After 10 days, pustules scattered around the periphery of the colony. Diffusing pigment not developed.

Distribution. China. Yunnan and Sichuan.

Additional specimen examined. China. Sichuan, Huanglong Nature Reserve, $3561 \mathrm{~m}$ (altitude), isolated from soil, 25 September 2016, Z. Li (WT 34012).

Notes. Phylogenetically, Trichoderma shangrilaense is related to T. parapiluliferum (CBS 120921) (Fig. 1), but the sequence similarity of $r p b 2$ between these two species was $98.93 \%$ and the sequence similarity of $t e f 1-\alpha$ was $96.35 \%$. The sequence similarity of tef1- $\alpha$ with the ex-type culture G.J.S. 91-60 (GenBank accession no. AY937444) was only $92 \%$. Optimum temperature for growth of T. shangrilaense was $20{ }^{\circ} \mathrm{C}$, no growth occurred at $30^{\circ} \mathrm{C}$ as in T. parapiluliferum and conidiation structures consist of flat or cushion-shaped pustules, formed near the colony margin on MEA, SNA and CMD. Conidiophore main axis of Trichoderma parapiluliferum has conspicuous spiral sterile apical elongations, conidia ellipsoidal to oblong (Lu et al. 2004). Conidiophore main axis of $T$. shangrilaense fertile to apex, conidia obovoid to ellipsoid, easily distinguished from that of T. parapiluliferum.

\section{Trichoderma vadicola G.Z. Zhang, sp. nov.}

MycoBank no: MB 821316

Fig. 7

Etymology. The specific epithet "vadicola", from the noun "vadum", reflects the ecological environment and means that the species inhabits shallow water.

Typification. China. Shandong, $2 \mathrm{~m}$ (altitude), isolated from soil, 13 August 2016, G.Z. Zhang (Holotype WT 10708), Ex-type culture ACCC 39716.

Diagnosis. Phylogenetically, Trichoderma vadicola is related to T. caerulescens in the Viride clade (Fig. 1), but the sequence similarity of tef1- $\alpha$ and $r p b 2$ between these species was all 95\%. Morphologically, colonies of T. vadicola and T. caerulescens on PDA 

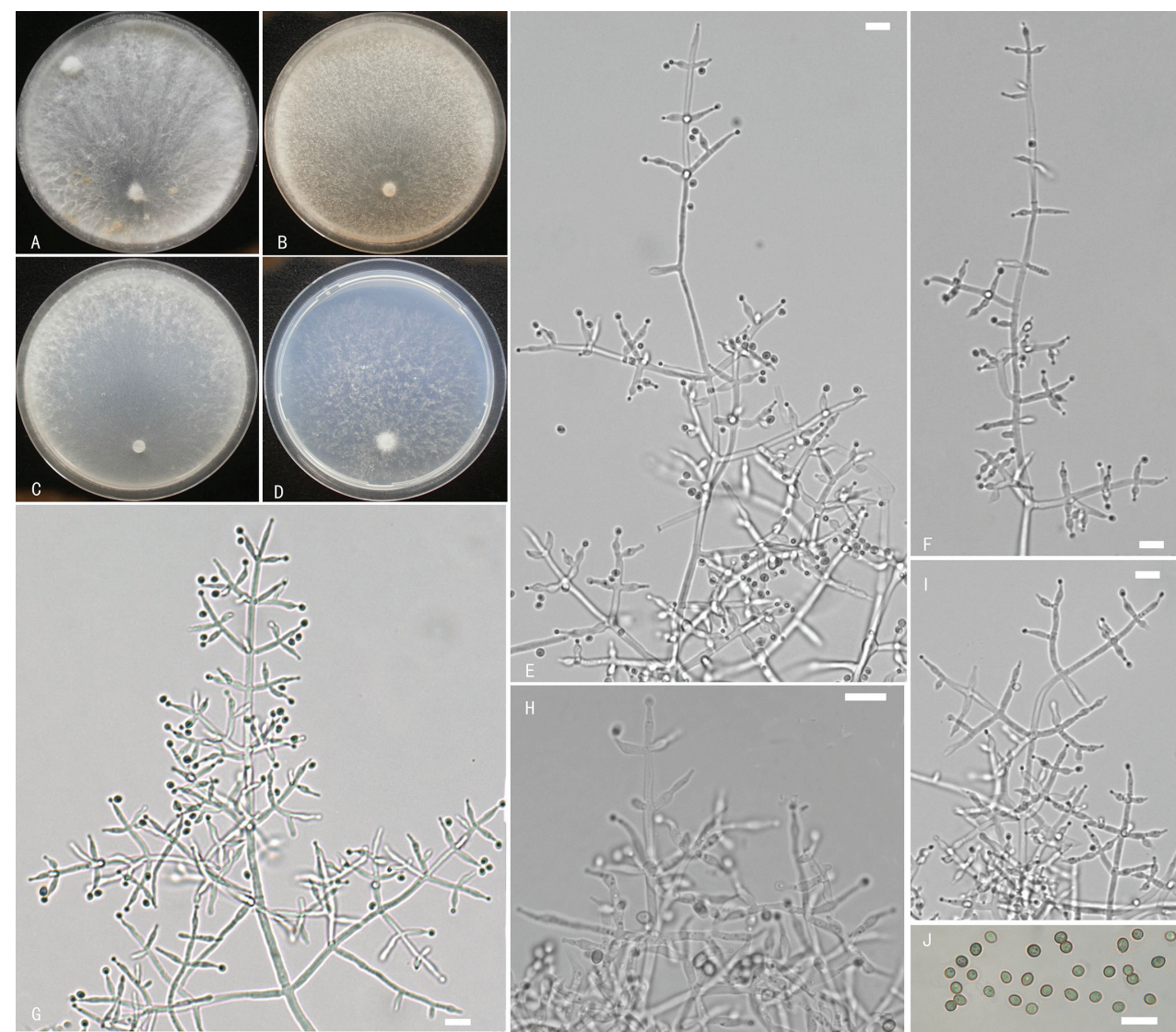

Figure 7. Trichoderma vadicola $\mathbf{A}-\mathbf{D}$ cultures on different media at $25^{\circ} \mathrm{C}(\mathbf{A}$ on PDA after 10 days $\mathbf{B}$ on MEA, after 7 days $\mathbf{C}$ on CMD after 7 days $\mathbf{D}$ on SNA after 7 days) $\mathbf{E}-\mathbf{I}$ conidiophores and phialides J conidia. Notes: E, F, H-J on MEA G on SNA A-J from WT10708. Scale bars: $10 \mu \mathrm{m}(\mathbf{E}-\mathbf{J})$.

have similar features, such as abundant aerial hyphae, forming strands and a whitish hairy or floccose mat. However, the former Trichoderma vadicola formed no or relatively few conidia and the latter forming greyish-bluish patches around the plug. On CMD, T. caerulescens peculiar greyish-blue pigment formed after 1-2 months and conidiophores simply or slightly branched; the former had no observed diffusing pigment and conidiophores branched in a complex manner in pyramidal structure or tree-like.

Teleomorph. Unknown.

Growth optimal at $25^{\circ} \mathrm{C}$, no grow at $35^{\circ} \mathrm{C}$ on all media. Colony radius after $72 \mathrm{~h}$ at $25^{\circ} \mathrm{C} 25-29 \mathrm{~mm}$ on PDA, 24-27 mm on CMD, 23-26 mm on MEA and 22-26 mm on SNA. Aerial mycelia abundant on PDA after $72 \mathrm{~h}$ at $25^{\circ} \mathrm{C}$ under $12 \mathrm{~h}$ photoperiod, forming strands and floccose mat. Conidiation not formed or relatively few. No diffusing pigment or distinctive odour was produced. On MEA after $72 \mathrm{~h}$ at $25^{\circ} \mathrm{C}$ under $12 \mathrm{~h}$ photoperiod, aerial mycelia abundant, floccose. After 7 days, mycelia covered the plate and conidia appeared, effuse, granuliform. On CMD after $72 \mathrm{~h}$ 
at $25^{\circ} \mathrm{C}$ under $12 \mathrm{~h}$ photoperiod, aerial mycelia not observed. After 7 days, mycelia covered the plate and conidia developed near the colony margin. On SNA after $72 \mathrm{~h}$ at $25^{\circ} \mathrm{C}$ under $12 \mathrm{~h}$ photoperiod, aerial mycelia not observed. After 7 days, mycelia covered the plate, aerial mycelia floccose and conidia formed, effuse. Conidiophores and branches regularly verticillate, formed a pyramidal structure, each branch terminating in a cruciate whorl of 3-5 phialides. Phialides lageniform, (8.3-)9.9-12.3(-15.1) $\times$ $(2.0-) 2.6-3.2(-3.4) \mu \mathrm{m}($ mean $=11.1 \times 2.9 \mu \mathrm{m}), 1.1-2.9 \mu \mathrm{m}$ wide $($ mean $=1.9 \mu \mathrm{m})$ near the base; phialide length/width ratio $(2.7-) 3.2-4.6(-6.6)($ mean $=3.9)$. Conidia subglobose or obovoidal, $(3.5-) 3.7-4.3(-4.8) \times(3.2-) 3.4-3.6(-3.8) \mu \mathrm{m}$ (mean $=4.0$ $\times 3.5 \mu \mathrm{m})$, length/width ratio 1.0-1.3 (mean $=1.1)$. Chlamydospores not observed.

Distribution. China. Shandong and Yunnan Provinces.

Additional specimen examined. China. Yunnan, Shangri-La, Pudacuo National Park, $3551 \mathrm{~m}$ (altitude), isolated from soil, 21 September 2016, H.T. Yang (WT 10713).

Notes. Phylogenetically, Trichoderma vadicola is related to T. caerulescens in the Viride clade (Fig. 1), but the sequence similarity of tefl- $\alpha$ and $r p b 2$ between these species was all 95\%, with 62 and 60 bp differences amongst 1218 and 1130 bp, respectively. Morphologically, colonies of T. vadicola and T. caerulescens on PDA have similar features, such as abundant aerial hyphae, forming strands and a whitish hairy or floccose mat. However, the former Trichoderma vadicola formed no or relatively few conidia, with the latter forming greyish-bluish patches around the plug. On CMD, T. caerulescens formed peculiar greyish-blue pigment after 1-2 months and conidiophores simply or slightly branched (Jaklitsch et al. 2012); the former had no observed diffusing pigment and conidiophores branched in a complex manner in pyramidal structure or tree-like.

\section{Discussion}

In this paper, five new species of Trichoderma were described from wetland soils. An ML tree was reconstructed, based on individual tef1- $\alpha$ and $r p b 2$, to explore the taxonomic positions of the new species. Our phylogenetic analyses showed that the five new Trichoderma species belong to the Polysporum clade or the Virde clade. Trichoderma macrofasciculatum and T. shangrilaense belong to the Polysporum clade (as Pachybasium core group; Jaklitsch 2011) (Fig. 2). Here, we added two new species, T. macrofasciculatum and T. shangrilaense, which are close to T. polysporum and T. parapiluliferum. Morphologically, species in this clade are heterogeneous, comprising teleomorphs with upright, stipitate or small pulvinate stromata. The teleomorphs of T. macrofasciculatum and T. shangrilaense have not been found at present, but their asexual characteristics, such as conidiation in white pustules, resemble other species in this clade.

Trichoderma nordicum, T. vadicola, and T. hailarense belong to the Viride clade (formerly section Trichoderma) (Fig. 1). Here, we added three new species, T. hailarense T. nordicum and T. vadicola, which are all located in the unnamed branches and close 
to T. gamsiil T. neokoningii, T. paratroviride and T. caerulescens, respectively. Phenotypically, phialides of three new species are lageniform and have green conidia, which is consistent with the characteristics of Trichoderma species in the Viride clade. Only T. hailarense has coarsely warted conidia, two other species being smooth-walled.

At present, the identification of Trichoderma species is mainly based on phylogenetic analysis and morphological characteristics. The new species hypothesis needs to be supported by the topology of both phylograms (rpb2 and tefl- $\alpha$ ). However, there are no numerical standards of the similarity threshold at the level which is sufficient for identification for most of the existing species (Cai and Druzhinina 2021) and this has led to many inaccuracies in the original identification of Trichoderma. In the phylogenetic tree constructed in this paper, some Trichoderma species combinations showed low bootstrap values (Figs 1 and 2) and have high similarity, which meet the $s p \exists !\left(r p b 2_{99} \cong t e f 1_{97}\right)$ standard developed by Cai and Druzhinina (2021). They may be identified as the same Trichoderma species: for example, T. viridialbum, T. viridarium and T. sempervirentis, which belong to the Trichoderma viridescens complex (Jaklitsch et al. 2013), may still be identified as T. viridescens. T. paraviridescens, T. trixiae and T. appalachiense may be identified as the same Trichoderma species.

Trichoderma species cannot be identified by phylogenetic analysis without considering the sequence similarity values. Therefore, Cai and Druzhinina (2021) developed a protocol for molecular identification of Trichoderma that requires analysis of the three DNA barcodes (ITS, tef1- $\alpha$ and rpb2). Molecular identification of Trichoderma species can be achieved, based on the analysis of sequence similarities between the query strain and the reference strains that are analysed for tef1- $\alpha(\geq 97 \%)$ and $r p b 2(\geq 99 \%)$. If this condition is not met, the query strain may be a new species of Trichoderma and the new species hypothesis can be made, based on sequence similarities and phylogenetic concordance, i.e. analysis of single loci tree topologies for tefl- $\alpha$ and $r p b 2$ and must be verified, based on morphology. In the identification process of the new species, we made full reference to this protocol and there were sufficient differences in sequence similarity between the newly-identified species and the reference species, as well as significant differences in morphological characteristics. According to Jaklitsch et al. (2013), the morphology of T. viridialbum, T. viridarium and T. sempervirentis (meeting the $s p \exists$ ! $\left(r p b 2_{99} \cong t e f 1_{97}\right)$ standard) shows a high degree of similarity and should still be identified as T. viridescens. This also fully verified that the identification protocol developed by Cai and Druzhinina (2021) is helpful to ensure the accuracy of Trichoderma species identification, which is worth promoting and applying, especially for the identification of Trichoderma species.

\section{Acknowledgements}

The authors sincerely thank Jin Dong Hu, Zhe Li and Ji Shun Li for providing the soil specimens. The authors are grateful to Konstanze Bensch for advising on the Latin names. This work was financed by the Shandong Key Research and Development 
Project (2014GSF121028; 2019GSF107086), Shandong Major Science and Technology innovation project (2019JZZY020610) and National Natural Science Foundation of China (Project no. 31700426; 31901928).

\section{References}

Atanasova L, Druzhinina IS, Jaklitsch WM (2013) Two hundred Trichoderma species recognized on the basis of molecular phylogeny. In: Mukherjee PK, Horwitz BA, Singh US, Mukherjee M, Schmoll M (Eds) Trichoderma: biology and applications. CAB International, Croydon, 10-42. https://doi.org/10.1079/9781780642475.0010

Bissett J (1991) A revision of the genus Trichoderma III. Infrageneric classification. Canadian Journal of Botany-revue Canadienne de botanique 69: 2372-2417. https://doi. org/10.1139/b91-297

Bissett J, Gams W, Jaklitsch W, Samuels GJ (2015) Accepted Trichoderma names in the year 2015. IMA Fungus 6(2): 263-295. https://doi.org/10.5598/imafungus.2015.06.02.02

Bustamante DE, Calderon MS, Leiva S, Mendoza JE, Arce M, Oliva M (2021) Three new species of Trichoderma in the Harzianum and Longibrachiatum lineages from Peruvian cacao crop soils based on an integrative approach. Mycologia 113(5): 1056-1072. https://doi.or $\mathrm{g} / 10.1080 / 00275514.2021 .1917243$

Cai F, Druzhinina IS (2021) In honor of John Bissett: authoritative guidelines on molecular identification of Trichoderma. Fungal Diversity 107: 1-69. https://doi.org/10.1007/ s13225-020-00464-4

Carbone I, Kohn LM (1999) A method for designing primer sets for speciation studies in filamentous ascomycetes. Mycologia 91(3): 553-556. https://doi.org/10.1080/00275514 .1999 .12061051

Chaverri P, Samuels GJ (2003) Hypocreal Trichoderma (Ascomycota, Hypocreales, Hypocreaceae), Species with green ascospores. Studies in Mycology 48: 1-116.

Chaverri P, Gazis RO, Samuels GJ (2011) Trichoderma amazonicum, a new endophytic species on Hevea brasiliensis and H. guianensis from the Amazon Basin. Mycologia 103(1): 139-151. https://doi.org/10.3852/10-078

Chen K, Zhuang WY (2016) Trichoderma shennongjianum and Trichoderma tibetense, two new soil-inhabiting species in the Strictipile clade. Mycoscience 57(5): 311-319. https://doi. org/10.1016/j.myc.2016.04.005

Chen K, Zhuang WY (2017a) Three new soil-inhabiting species of Trichoderma in the Stromaticum clade with test of their antagonism to pathogens. Current Microbiology 74(9): 1049-1060. https://doi.org/10.1007/s00284-017-1282-2

Chen K, Zhuang WY (2017b) Seven new species of Trichoderma from soil in China. Mycosystema 36(11): 1441-1462.

Chen K, Zhuang WY (2017c) Seven soil-inhabiting new species of the genus Trichoder$m a$ in the Viride clade. Phytotaxa 312(1): 28-46. https://doi.org/10.11646/phytotaxa.312.1.2

Chen K, Zhuang WY (2017d) Discovery from a large-scaled survey of Trichoderma in soil of China. Scientific Reports 7(1): e9090. https://doi.org/10.1038/s41598-017-07807-3 
Crous PW, Wingfield MJ, Lombard L, Roets F, Swart WJ, Alvarado P, Carnegie AJ, Moreno G, Luangsa-ard J, Thangavel R, Alexandrova AV, Baseia IG, Bellanger J-M, Bessette AE, Bessette AR, la Peńa-Lastra SDe, García D, Gené J, Pham THG, Heykoop M, Malysheva E, Malysheva V, Martín MP, Morozova OV, Noisripoom W, Overton BE, Rea AE, Sewall BJ, Smith ME, Smyth CW, Tasanathai K, Visagie CM, Adamčík S, Alves A, Andrade JP, Aninat MJ, Araújo RVB, Bordallo JJ, Boufleur T, Baroncelli R, Barreto RW, Bolin J, Cabero J, Caboň M, Cafâ G, Caffot MLH, Cai L, Carlavilla JR, Chávez R, de Castro RRL, Delgat L, Deschuyteneer D, Dios MM, Domínguez LS, Evans HC, Eyssartier G, Ferreira BW, Figueiredo CN, Liu F, Fournier J, Galli-Terasawa LV, Gil-Durán C, Glienke C, Gonçalves MFM, Gryta H, Guarro J, Himaman W, Hywel-Jones N, Iturrieta-González I, Ivanushkina NE, Jargeat P, Khalid AN, Khan J, Kiran M, Kiss L, Kochkina GA, Kolař́k M, Kubátová A, Lodge DJ, Loizides M, Luque D, Manjón JL, Marbach PAS, Massola Jr NS, Mata M, Miller AN, Mongkolsamrit S, Moreau P-A, Morte A, Mujic A, Navarro-Ródenas A, Németh MZ, Nóbrega TF, Nováková A, Olariaga I, Ozerskaya SM, Palma MA, Petters-Vandresen DAL, Piontelli E, Popov ES, Rodríguez A, Requejo Ó, Rodrigues ACM, Rong IH, Roux J, Seifert KA, Silva BDB, Sklenár F, Smith JA, Sousa JO, Souza HG, De Souza JT, Švec K, Tanchaud P, Tanney JB, Terasawa F, Thanakitpipattana D, Torres-Garcia D, Vaca I, Vaghefi N, van Iperen AL, Vasilenko OV, Verbeken A, Yilmaz N, Zamora JC, Zapata M, Jurjević Ž, Groenewald JZ (2019) Fungal Planet description sheets: 951-1041. Persoonia 43: 223-425. https://doi.org/10.3767/persoonia.2019.43.06

Ding MY, Chen W, Ma XC, Lv BW, Jiang SQ, Yu YN, Rahimi MJ, Gao RW, Zhao Z, Cai D, Druzhinina IS (2020) Emerging salt marshes as a source of Trichoderma arenarium sp. nov. and other fungal bioeffectors for biosaline agriculture. Journal of Applied Microbiology 130: 179-195. https://doi.org/10.1111/jam.14751

Dodd SL, Lieckfeldt E, Samuels GJ (2003) Hypocrea atroviridis sp. nov., the teleomorph of Trichoderma atroviride. Mycologia 95(1): 27-40. https://doi.org/10.1080/15572536.200 4.11833129

Dou K, Lu Z, Wu Q, Ni M, Yu C, Wang M, Li Y, Wang X, Xie H, Chen J, Zhang C (2020) MIST: a multilocus identification system for Trichoderma. Applied and Environmental Microbiology 86(18): e01532-20. https://doi.org/10.1128/AEM.01532-20

Druzhinina IS, Kopchinskiy AG, Kubicek CP (2006) The first 100 Trichoderma species characterized by molecular data. Mycoscience 47(2): 55-64. https://doi.org/10.1007/S10267006-0279-7

du Plessis IL, Druzhinina IS, Atanasova L, Yarden O, Jacobs K (2018) The diversity of Trichoderma species from soil in South Africa with five new additions. Mycologia 110(3): 59-583. https://doi.org/10.1080/00275514.2018.1463059

Gams W, Bissett J (1998) Morphology and identification of Trichoderma. In: Kubicek CP, Harman GE (Eds) Trichoderma and Gliocladium. Vol. 1. Basic biology, taxonomy and genetics. Taylor and Francis Ltd., Lindon, 3-34.

Gu X, Wang R, Sun Q, Wu B, Sun JZ (2020) Four new species of Trichoderma in the Harzianum clade from northern China. MycoKeys 73: 109-132. https://doi.org/10.3897/ mycokeys.73.51424

Hasegawa M, Kishino H, Yano T (1985) Dating the human-ape split by a molecular clock of mitochondrial DNA. Journal of Molecular Evolution 22(2): 160-174. https://doi. org/10.1007/BF02101694 
Thompson JD, Higgins DG, Gibson TJ (1994) CLUSTAL W: improving the sensitivity of progressive multiple sequence alignment through sequence weighting, position-specific gap penalties and weight matrix choice. Nucleic Acids Research 22(22): 4673-4680. https:// doi.org/10.1093/nar/22.22.4673

Jaklitsch WM, Komon M, Kubicek CP, Druzhinina IS (2005) Hypocrea voglmayrii sp. nov. from the Austrian Alps represents a new phylogenetic clade in Hypocreal Trichoderma. Mycologia 97(6): 1365-1378. https://doi.org/10.3852/mycologia.97.6.1365

Jaklitsch WM, Komon M, Kubicek CP, Druzhinina IS (2006) Hypocrea crystalligena sp. nov., a common European species with a white-spored Trichoderma anamorph. Mycologia 98(3): 499-513. https://doi.org/10.3852/mycologia.98.3.499

Jaklitsch WM (2009) European species of Hypocrea Part I. The green-spored species. Studies in Mycology 63: 1-91. https://doi.org/10.3114/sim.2009.63.01

Jaklitsch WM (2011) European species of Hypocrea Part II: species with hyaline ascospores. Fungal Diversity 48(1): 1-250. https://doi.org/10.1007/s13225-011-0088-y

Jaklitsch WM, Stadler M, Voglmayr H (2012) Blue pigment in Hypocrea caerulescens sp. nov. and two additional new species in sect. Trichoderma. Mycologia 104: 925-941. https:// doi.org/10.3852/11-327

Jaklitsch WM, Samuels GJ, Ismaiel A, Voglmayr H (2013) Disentangling the Trichoderma viridescens complex. Persoonia 31: 112-146. https://doi.org/10.3767/003158513X672234

Jaklitsch WM, Voglmayr H (2015) Biodiversity of Trichoderma (Hypocreaceae) in Southern Europe and Macaronesia. Studies in Mycology 80: 1-87. https://doi.org/10.1016/j.simyco.2014.11.001

Kimura M (1980) A simple method for estimating evolutionary rate of base substitutions through comparative studies of nucleotide sequences. Journal of Molecular Evolution 16(2): 111-120. https://doi.org/10.1007/BF01731581

Kindermann J, El-Ayouti Y, Samuels GJ, Kubicek CP (1998) Phylogeny of the genus Trichoderma based on sequence analysis of the internal transcribed spacer region 1 of the rDNA cluster. Fungal Genetics and Biology 24(3): 298-309. https://doi.org/10.1006/fgbi.1998.1049

Kornerup A, Wanscher JH (1978) Methuen Handbook of Colour, $3^{\text {rd }}$ edn. Sankt Jørgen Tryk, Copenhagen.

Kredics L, Hatvani L, Naeimi S, Körmöczi P, Manczinger L, Vágvölgyi C, Druzhinina I (2014) Biodiversity of the genus HypocrealTrichoderma in different habitats. In: Gupta VK, Schmoll M, Herrera-Estrella M, Upadhyay RS, Druzhinina I, Tuohy MG (Eds) Biotechnology and biology of Trichoderma. Elsevier, Waltham, 3-18. https://doi.org/10.1016/ B978-0-444-59576-8.00001-1

Kubicek CP, Komon-Zelazowska M, Druzhinina IS (2008) Fungal genus Hypocreal Trichoderma: from barcodes to biodiversity. Journal of Zhejiang University Science B 9(10): 753-763. https://doi.org/10.1631/jzus.B0860015

Kullnig-Gradinger CM, Szakacs G, Kubicek CP (2002) Phylogeny and evolution of the fungal genus Trichoderma: a multigene approach. Mycological Research 106: 757-767. https:// doi.org/10.1017/S0953756202006172

Kumar S, Stecher G, Li M, Knyaz C, Tamura K (2018) MEGA X: Molecular Evolutionary Genetics Analysis across computing platforms. Molecular Biology and Evolution 35(6): 1547-1549. https://doi.org/10.1093/molbev/msy096 
Li J, Wu Y, Chen K, Wang Y, Hu J, Wei Y, Yang H (2018) Trichoderma cyanodichotomus sp. nov., a new soil-inhabiting species with a potential for biological control. Canadian Journal of Microbiology 64(12): 1020-1029. https://doi.org/10.1139/cjm-2018-0224

Liu YL, Whelen S, Hall BD (1999) Phylogenetic relationships among ascomycetes: evidence from an RNA polymerase II subunit. Molecular Biology and Evolution 16(12): 17991808. https://doi.org/10.1093/oxfordjournals.molbev.a026092

Liu SY, Yu Y, Zhang TY, Zhang MY, Zhang YX (2020) Trichoderma panacis sp. nov., an endophyte isolated from Panax notoginseng. International Journal of Systematic and Evolutionary Microbiology 70(5): 3162-3166. https://doi.org/10.1099/ijsem.0.004144

Lu B, Druzhinina IS, Fallah P, Chaverri P, Gradinger C, Kubicek CP, Samuels GJ (2004) Hypocreal Trichoderma species with pachybasium-like conidiophores: sexual morphs for T. minutisporum and T. polysporum and their newly discovered relatives. Mycologia 96(2): 310-342. https://doi.org/10.1080/15572536.2005.11832980

Martin J (1950) Use of acid, rose bengal and streptomycin in the plate method for estimating soil fungi. Soil Science 69(3): 215-232. https://doi.org/10.1097/00010694-195003000-00006

Montoya QV, Meirelles LA, Chaverri P, Rodrigues A (2016) Unraveling Trichoderma species in the attine ant environment: description of three new taxa. Antonie van Leeuwenhoek 109(5): 633-651. https://doi.org/10.1007/s10482-016-0666-9

Mukherjee PK, Horwitz BA, Singh U, Mukherjee M, Schmoll M (2013) Trichoderma in agriculture, industry and medicine: an overview. In: Mukherjee PK, Horwitz BA, Singh US, Mukherjee M, Schmoll M (Eds) Trichoderma: biology and applications. CAB International, Croydon, 1-7. https://doi.org/10.1079/9781780642475.0001

Nirenberg HI (1976) Untersuchungen über die morphologische und biologische Differenzierung in der Fusarium-Sektion Liseola. Mitteilungen aus der Biologischen Bundesanstalt für Land-und Forstwirtschaft 169: 1-117.

Park MS, Oh SY, Cho HJ, Fong JJ, Cheon WJ, Lim YW (2014) Trichoderma songyi sp. nov., a new species associated with the pine mushroom (Tricholoma matsutake). Antonie van Leeuwenhoek 106(4): 593-603. https://doi.org/10.1007/s10482-014-0230-4 [Epub 2014 Jul 23]

Qiao M, Du X, Zhang Z, Xu JP, Yu ZF (2018) Three new species of soil-inhabiting Trichoderma from southwest China. MycoKeys 44: 63-80. https://doi.org/10.3897/mycokeys.44.30295

Qin WT, Zhuang WY (2016a) Seven wood-inhabiting new species of the genus Trichoderma (Fungi, Ascomycota) in Viride clade. Scientific Reports 6: e27074. https://doi. org/10.1038/srep27074

Qin WT, Zhuang WY (2016b) Four new species of Trichoderma with hyaline ascospores in the Brevicompactum and Longibrachiatum clades. Mycosystema 35(11): 1317-1336. https:// doi.org/10.13346/j.mycosystema.160158

Qin WT, Zhuang WY (2016c) Two new hyaline-ascospored species of Trichoderma and their phylogenetic positions. Mycologia 108(1): 205-214. https://doi.org/10.3852/15-144

Qin WT, Zhuang WY (2017) Seven new species of Trichoderma (Hypocreales) in the Harzianum and Strictipile clades. Phytotaxa 305(3): 121-139. https://doi.org/10.11646/phytotaxa.305.3.1

Rodríguez María del CH, Evans HC, de Abreu LM, de Macedo DM, Ndacnou MK, Bekele KB, Barreto RW (2021) New species and records of Trichoderma isolated as mycoparasites 
and endophytes from cultivated and wild coffee in Africa. Scientific Reports 11: e5671. https://doi.org/10.1038/s41598-021-84111-1

Samuels GJ (2006) Trichoderma: systematics, the sexual state, and ecology. Phytopathology 96: 195-206. https://doi.org/10.1094/PHYTO-96-0195

Samuels GJ, Dodd S, Lu BS, Petrini O, Schroers HJ, Druzhinina IS (2006) The Trichoderma koningii aggregate species. Studies in Mycology 56: 67-133. https://doi.org/10.3114/ sim.2006.56.03

Sun J, Pei Y, Li E, Li W, Hyde KD, Yin WB, Liu X (2016) A new species of Trichoderma hypoxylon harbours abundant secondary metabolites. Scientific Reports 6: e37369. https:// doi.org/10.1038/srep37369

Tamura K, Nei M (1993) Estimation of the number of nucleotide substitutions in the control region of mitochondrial DNA in humans and chimpanzees. Molecular Biology and Evolution 10(3): 512-526. https://doi.org/10.1093/oxfordjournals.molbev.a040023

Tomah AA, Alamer IS, Li B, Zhang JZ (2020) A new species of Trichoderma and gliotoxin role: A new observation in enhancing biocontrol potential of T. virens against Phytophthora capsici on chili pepper. Biological Control 145: 104261. https://doi.org/10.1016/j.biocontrol.2020.104261

Tripathi P, Singh PC, Mishra A, Chauhan PS, Dwivedi S, Bais RT, Tripathi RD (2013) Trichoderma: a potential bioremediator for environmental clean up. Clean Technologies and Environmental Policy 15(4): 541-550. https://doi.org/10.1007/s10098-012-0553-7

White TJ, Bruns T, Lee S, Taylor J (1990) Amplification and direct sequencing of fungal ribosomal RNA genes for phylogenetics. In: Innis MA, Gelfand DH, Sninsky JJ et al. (Eds) PCR protocols: a guide to methods and applications. Academic Press, San Diego, 315322. https://doi.org/10.1016/B978-0-12-372180-8.50042-1

Zeng ZQ, Zhuang WY (2017) Phylogenetic position of Pseudohypocrea (Hypocreales). Mycoscience 58(4): 274-281. https://doi.org/10.1016/j.myc.2017.04.005

Zeng ZQ, Zhuang WY (2019) Two new species and a new Chinese record of Hypocreaceae as evidenced by morphological and molecular data. Mycobiology 47(3): 280-291. https:// doi.org/10.1080/12298093.2019.1641062

Zhang YB, Zhuang WY (2017) Four new species of Trichoderma with hyaline ascospores from southwest China. Mycosphere 8(10): 1914-1929. https://doi.org/10.5943/mycosphere/8/10/14

Zhang YB, Zhuang WY (2018) New species of Trichoderma in the Harzianum, Longibrachiatum and Viride clades. Phytotaxa 379(2): 131-142. https://doi.org/10.11646/phytotaxa.379.2.1

Zhang YB, Zhuang WY (2019) Trichoderma bomiense and T. viridicollare, two new species forming separate terminal lineages among the green-ascospored clades of the genus. Mycosystema 38(1): 11-22. https://doi.org/10.13346/j.mycosystema.180304

Zheng H, Qiao M, Lv YF, Du X, Zhang KQ, Yu ZF (2021) New species of Trichoderma isolated as endophytes and saprobes from southwest China. Journal of Fungi 7(6): e467. https://doi.org/10.3390/jof7060467 
Zhao YZ, Zhang ZF, Cai L, Peng WJ, Liu F (2018) Four new filamentous fungal species from newly-collected and hive-stored bee pollen. Mycosphere 9(6): 1089-1116. https://doi. org/10.5943/mycosphere/9/6/3

Zhu ZX, Zhuang WY (2015a) Three new species of Trichoderma with hyaline ascospores from China. Mycologia 107(2): 328-345. https://doi.org/10.3852/14-141

Zhu ZX, Zhuang WY (2015b) Trichoderma (Hypocrea) species with green ascospores from China. Persoonia 34: 113-129. https://doi.org/10.3767/003158515X686732

Zhu ZX, Zhuang WY (2018) A new species of the Longibrachiatum clade of Trichoderma (Hypocreaceae) from northeast China. Nova Hedwigia 106(3-4): 441-453. https://doi. org/10.1127/nova_hedwigia/2017/0444

\section{Supplementary material I}

\section{Five new species of Trichoderma from moist soils in China}

Authors: Guang-Zhi Zhang, He-Tong Yang, Xin-Jian Zhang, Fang-Yuan Zhou, XiaoQing Wu, Xue-Ying Xie, Xiao-Yan Zhao, Hong-Zi Zhou

Data type: COL

Explanation note: Trichoderma hailarense G.Z. Zhang, sp. nov.; Trichoderma macrofasciculatum G.Z. Zhang, sp. nov.; Trichoderma nordicum G.Z. Zhang, sp. nov.; Trichoderma shangrilaense G.Z. Zhang, sp. nov.; Trichoderma vadicola G.Z. Zhang, sp. nov.

Copyright notice: This dataset is made available under the Open Database License (http://opendatacommons.org/licenses/odbl/1.0/). The Open Database License $(\mathrm{ODbL})$ is a license agreement intended to allow users to freely share, modify, and use this Dataset while maintaining this same freedom for others, provided that the original source and author(s) are credited.

Link: https://doi.org/10.3897/mycokeys.87.76085.suppl1 